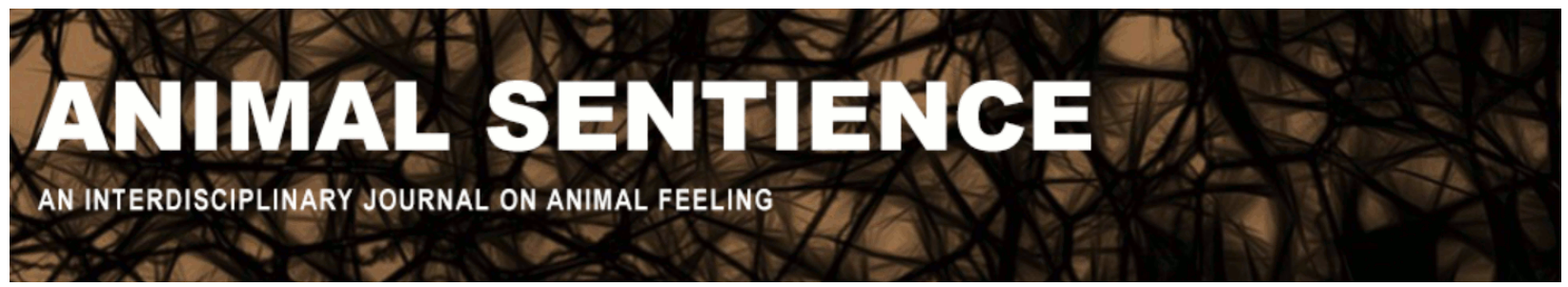

Monsó, Susana (2016) The moral dimension of pre-reflective self-awareness. Animal Sentience 10(7)

DOI: $10.51291 / 2377-7478.1144$

Date of submission: 2016-08-14

Date of acceptance: 2016-08-18

(c)

This article has appeared in the journal Animal

Sentience, a peer-reviewed journal on animal

cognition and feeling. It has been made open access,

free for all, by WellBeing International and deposited

in the WBI Studies Repository. For more information,

please contact

wbisr-info@wellbeingintl.org.

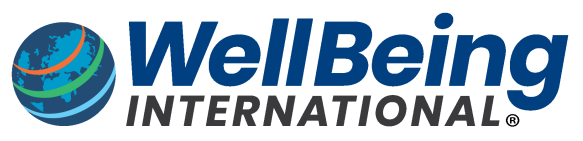

SOLUTIONS FOR PEOPLE, ANIMALS AND ENVIRONMENT 


\title{
The moral dimension of pre-reflective self-awareness
}

\author{
Commentary on Rowlands on Animal Personhood
}

\author{
Susana Monsó \\ Department of Logic, History and Philosophy of Science \\ Universidad Nacional de Educación a Distancia (UNED), Madrid
}

\begin{abstract}
Rowlands offers a de-intellectualised account of personhood that is meant to secure the unity of a mental life. I argue that his characterisation also singles out a morally relevant feature of individuals. Along the same lines that the orthodox understanding of personhood reflects a fundamental precondition for moral agency, Rowlands's notion provides a fundamental precondition for moral patienthood.
\end{abstract}

Keywords: moral agency, moral patienthood, self-awareness, sentience, personhood

\begin{abstract}
Susana Monsó holds a PhD in philosophy and is affiliated with the Department of Logic, History, and Philosophy of Science at UNED, Madrid, and the Unit of Ethics and HumanAnimal Studies at the Messerli Research Institute, Vienna. Her work focuses on the intersection between debates on animal cognition, animal morality, and animal ethics. http://philpapers.org/profile/32342/
\end{abstract}

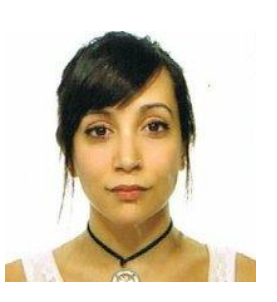

In the target article, Rowlands (2016) constructs a notion of personhood that can account for the unity of the mental life of an individual while letting go of the requirement for metacognitive capacities. The way he does this is by introducing the notion of pre-reflective self-awareness. This is distinguished from reflective self-awareness, which is the standard way of understanding the capacity that unifies our mental life and grants us personhood. Reflective self-awareness comprises all higher-order intentional acts that take our own bodies or mental states as their objects. Given the generalised scepticism about (most) nonhuman animals' ability to engage in reflective self-awareness thus understood, this is often interpreted as meaning that only humans, and perhaps a handful of nonhuman species, are persons.

Rowlands offers a compelling argument to show that we cannot appeal to reflective self-awareness in order to account for the unity of a mental life, because that only works if we beg the question and presuppose that the mental life is unified to begin with. Instead, he argues, the unity of our mental lives is grounded in our pre-reflective self-awareness, an awareness of ourselves that is implicit in all our conscious experiences and that, it seems plausible to suppose, is much more widely distributed in nature than its reflective counterpart. This would mean that the category of person is one that applies to many more species than is commonly granted.

In this commentary, I want to draw attention to the moral dimension of the notion of pre-reflective self-awareness that grounds Rowlands's conceptualisation of personhood. At the outset of his target article, Rowlands (2016) specifies that he is only concerned with the metaphysical notion of person, and not with the moral one (pp. 1-2). However, as I intend to 
argue, the concept of personhood he puts forward is not neutral from a moral standpoint, but rather, comprises a morally relevant feature of individuals.

The orthodox understanding of the metaphysical person is closely linked to the orthodox understanding of the moral person. Dennett (1976), for instance, describes the metaphysical person as "roughly, ... an intelligent, conscious, feeling agent," and the moral person as "roughly, ... an agent who is accountable, who has both rights and responsibilities" (p. 176). Dennett (1976) considers the former to be a necessary condition for the latter, so that one cannot be a moral person without being a metaphysical person (pp. 178-9).

If we take accountability or moral responsibility to be the hallmark of moral personhood - thus bringing the notion of a moral person close to that of a moral agent then there appears to be every reason to link it to the standard understanding of a metaphysical person, i.e., as one who can engage in reflective self-awareness. Indeed, reflective self-awareness is commonly thought to be the ability that grants humans a form of control over our motivations and actions that makes us morally responsible for what we do (a view that is endorsed by Dennett, 1976, pp. 192-3). Elsewhere, Rowlands (2012) has argued that considering that reflective self-awareness can grant us control over our motivations and actions is also begging the question, because it only works if we presuppose that we have control over our higher-order reflections to begin with (Chapter 7). Nevertheless, he too regards reflective self-awareness as a crucial characteristic of moral agents, insofar as it enables the reflection upon, and subsequent understanding of, one's motivations, which is also at the core of moral responsibility (Chapter 9).

The metaphysical notion of personhood outlined by Rowlands (2016), in contrast to the orthodox characterisation, appears to be conceptually quite separated from the notion of moral agency. Considering that an individual has a unified mental life grounded in her prereflective self-awareness is very far from suggesting that she can be held morally responsible for her actions. Several other important and intellectually demanding conditions would have to be met by her. These include reflective self-awareness, but also, arguably, other conditions such as the possession of moral motivations, moral judgement, and mindreading capacities (Monsó, forthcoming). An individual who has reflective self-awareness is already considerably sophisticated cognitively because she can engage in higher-order thinking. So it is likely that she will have the remaining conditions for moral agency. In comparison, prereflective self-awareness is much less demanding. Indeed, there are reasons to think that it extends in nature as far as invertebrates (Jürgens, 2016, p. 2). Knowing that an individual is a metaphysical person in Rowlands's sense, therefore, tells us virtually nothing about whether she is a moral agent. However, it very strongly suggests that she is a moral patient.

Following Rowlands (2012), we can define a moral patient as a "legitimate object of moral concern" (p. 72). What counts as legitimate is, of course, going to depend on the normative ethics one subscribes to, but it seems that, at the very least, a being needs to have sentience in order to be an object of our moral concern, where sentience can be defined as "the capacity to feel" (Harnad, 2016, p. 3). Nussbaum (2007), for instance, states that

[s]entience is not the only thing that matters for basic justice; but it seems plausible to consider the possession of sentience as a threshold condition for membership in the community of beings who have entitlements based on justice. (pp. 361-2) 
While some would extend the moral community even further (e.g., Leopold, 1949), the widespread consensus amongst ethicists is captured in Nussbaum's quote. Once a being has sentience, whatever happens to her starts to matter to her because there is something that it is like to be her, so sentience appears to be a fundamental precondition for moral patienthood. This point is also endorsed by Rowlands (2009, pp. 159-60).

Rowlands's (2016) notion of personhood serves to distinguish those beings who have a unified mental life. But in addition, because of the way this notion is grounded in prereflective self-awareness, it also singles out those beings who are sentient. This is because pre-reflective self-awareness appears "[w] henever a subject has [conscious] experiences," and is, in fact, "part of what it is to have conscious experience" (Rowlands, 2016, p. 15). Conscious experience, in turn, is the hallmark of sentience, so wherever there is prereflective self-awareness, and thus personhood, there is going to be sentience. Therefore, analogous to the way the orthodox understanding of metaphysical personhood sets aside those beings who have a fundamental precondition for moral agency, Rowlands's notion individuates those beings who are potential candidates for moral patienthood.

\section{References}

Dennett, D. C. (1976). Conditions of personhood. In A. O. Rorty (Ed.), The Identities of Persons (pp. 176-96). Oakland: University of California Press.

Harnad, S. (2016). Animal sentience: The other-minds problem. Animal Sentience 2012.001.

Jürgens, U. M. (2016). Universal modes of awareness? A "pre-reflective" premise. Animal Sentience 2016.116.

Leopold, A. (1949). A Sand County Almanac and Sketches Here and There. New York: Oxford University Press.

Monsó, S. (forthcoming). Morality without mindreading. Mind \& Language.

Nussbaum, M. C. (2007). Frontiers of Justice: Disability, Nationality, Species Membership. Cambridge: Harvard University Press.

Rowlands, M. (2009). Animal Rights: Moral Theory and Practice (2nd edition). New York: Palgrave Macmillan.

Rowlands, M. (2012). Can Animals Be Moral? New York: Oxford University Press.

Rowlands, M. (2016). Are animals persons? Animal Sentience 2016.101. 